\title{
Determinants of Building 21st Century Skills in Palestinian Elementary Schools
}

\author{
Marwan M. A. Abualrob ${ }^{1}$ \\ ${ }^{1}$ Department of Elementary Education, Arab American University, Palestine \\ Correspondence: Marwan M. A. Abualrob, Elementary Education Department, Faculty of Arts. Arab American \\ University, P. O. BOX 240, Jenin-West Bank, Palestine. Tel: 970-599-473-155. E-mail: \\ marwan.abualrob@aaup.edu
}

Received: February 12, 2019

Accepted: February 26, 2019 Online Published: March 21, 2019

doi:10.5539/hes.v9n2p108

URL: https://doi.org/10.5539/hes.v9n2p108

\begin{abstract}
To fully engage in modern society, learners need to acquire not only individual skills- such as critical thinking, innovation and self-direction, but also participatory competences- such as collaboration, local connections, global connections, technology utilization and communication. The present study measures the factors influencing the development of such skills in the elementary stage science students in Palestine. The population comprised the science teachers for third through ninth grades at West Bank schools, while the sample consisted of 560 teacher respondents who provided self-assessment of their role in developing the 21 st skills in their students. A scale developed by Ravitz et al (2012) was used to test 48 practices across 8 major skill categories: Critical Thinking Skill, Collaboration Skills, Communication Skills, Innovation Skills, Self -Direction Skills, Global Connections Skills, Local Connections Skills and Technology Utilization. Our focus was on measuring results in relation to five teacher-related variables: sex, academic degree, years of experience, teacher major and active learning training. The findings suggest that these variables are crucial in skill-building.
\end{abstract}

Keywords: 21 st century skills, active learning, science teaching

\section{Introduction}

Speaking about education, British social critic, Bertrand Russell, says "We are faced with the paradoxical fact that education has become one of the chief obstacles to intelligence and freedom of thought" (Hunt, 1979, p. 127). Of course, these words still have validity to them. The very education systems in many counties around the world are still mired in processes that deliver general unfocused education that has no definitive boundaries, with objectives as broad as producing generations that have the knowledge needed in leading a successful life. Yet, the word "knowledge" takes us nowhere, as it has yet to be taken to mean "skill-building."

Much literature on recent behaviors of economies shows that the trends in markets are changing across the board. Though different structural elements can delineate a market's trajectory, it is the case that human capital remains the most important economic lever. This is particularly true for Palestine- an occupied territory with limited access to its own natural resources and foreign markets. That is why an investment in human capital remains the best possible driver for economic growth and development in Palestine.

History has taught us that countries which succeeded in improving their human capital are those that provide good schooling to their children. This includes, among other things, general knowledge in major disciplines as well as a wide range of skills: collaboration, critical thinking, innovation, technology utilization, self-direction, local connections, global connections, and communication (This is a list suggested by Ravitz et al, 2012). Of course, there are different practices that build a wide array of sub-skills within each individual category. The sub-skills, however, form a large interconnected web, such that some constructs are interdependent, i.e. acquiring a specific skill is contingent on acquiring other skills. Hence, it is not easy to talk about building a particular skill independently of other skills. This adds to the already difficult tasks of schools. For one, at a particular time, they might need to focus on one skill category. For another, that particular category cannot be addressed individually; other categories need to be considered simultaneously.

The premise that integrating the 21 st century skills would deliver good results is based on expectations that elementary school systems will be doing more for pupils than just focusing on preparing them for later academic 
exams (in high schools or universities). In a holistic sense, schools should work to provide pupils with the dexterity they need to become engaged thinkers, resilient and resourceful learners, creative problem solvers and active members of their communities.

In its recommendation section, a study by A., \& C. (2015) proposed a holistic approach which can ensure that Palestinian schools, colleges, and universities are providing applied, real-life and practical skills for students. Such a bottom-up approach to skill-building involves three levels: starting from the very basic elements of the system (i.e., schools), through university education and up to on-the job-training programs. While the third phase is expected to be done by businesses themselves and the second by individual universities, the first level remains the responsibility of the government.

Cognizant of the pressing need to build an economy that relies on an effective supply of skilled workers, the Palestinian planners have to start looking at the problem in a broader scope- seeing a skill gap that requires tackling. The Ministry of Education (MOE) has developed guidance methods and recommendations for cultivating the 21 st century skills at schools across different areas: teaching and teacher development/training, learning, assessment, curriculum presentation, and instructions. The Ministry's decision makers believe that all of these areas should be handled within a framework of technology-friendly environment. For this, the Ministry has supplied schools with computers, LCDs and internet access points, and the labs were extended in size to accommodate such technological appliances.

In its 2017-2022 strategic plan, the Palestinian Ministry of education provided an account of the challenges facing the current school education system. For example, it found that only 30 percent of the activities done in elementary schools can be said to be directed to skill-building, while 64 percent of activities are based on memorizing and abstract knowledge feed. A policy paper released in 2017 by the Ministry focused on two things: the need to incorporate 21st skills in the school curriculum, and building the capacity of the teachers to be able to develop such skills (MOE ,2017).

This is, however, easier said than done. Recent studies still show a skills mismatch between actual labor skills and the demands of the market. The findings of the A., \& C. (2015) have echoed well with the results reached by the Palestinian Ministry of Education's Monitoring and Evaluating Report (2013), as well as with the report by UN (2009). Both reports found that the education system has minimal content related to developing life skills, and that schools are still lagging behind in terms of nurturing and honing innovative dispositions. The reports proposed policy interventions that can address the existing gaps.

Within this context, a question is posed and it needs to be answered: Do science teachers at elementary schools in Palestine foster the development of the 21st century skills: particularly collaboration, critical thinking, innovation, technology utilization, self-direction, local connections, global connections, and communication?

Ramzi, Q. (2001) was perhaps the first to venture into the 21st century skills in Palestine. The author used a questionnaire to measure elementary school science students view of the role of their teachers in nurturing creative thinking skills in Ramallah, West Bank. She found the students relatively satisfied by their teachers' performance in this regard. She also found that female teachers and those with high diploma received higher scores by their students. A few years later, Zidan and Odeh (2007) measured the science teachers' integration of creative thinking skills at elementary schools in Hebron, West Bank, but the authors used teachers themselves as respondents. They found that the content and teaching methods are motivating and that students, as a result, have high creative thinking skills. The findings suggested significant differences correlated with teachers' years of experience: the more the years, the more the creative thinking in students.

Another study came from Gaza, but with bleak results this time. Naqa (2011) measured integration of creative thinking skills at high schools in Khan Younis, Gaza. The author built a test of different items, all intended to measure creative thinking and the speed with which students can respond to particular situations. Then he chose 76 students from different schools and gave them the test in one of the public schools in Khan Younis. The findings suggested poor creative thinking skills. In his interpretation of the results, Naqa discussed different factors that might have adversely affected performance: large number of students in classrooms, many units within textbooks, no creative thinking integration in lower stages (elementary schools), teachers' indifference toward nurturing such skills, students' focus on grades rather than on skills, and absence of skill-based assessment methods.

No matter where the discussion goes, it remains that a reliable account of the extent to which the 21 st century skills are incorporated into the teaching/learning process should consider not only aggregate figures, but also the roles of different variables in producing those figures. The question is: "Have the 21 st century skills found their way into our system of teaching and learning at schools?" This study considers the implications of this question 
for science students in Palestine's elementary schools. In particular, we measure the role of science teachers in developing the 21st century skills for the elementary stage students in Palestine. The effort is expected to provide the Palestinian decision-making community with a clearer picture of the actual teaching/learning practice at schools, so that decision makers would be able to formulate the policies that address the challenge at all possible levels- teachers, students, schools, administrators, curriculum, training, etc. We need to make it clear, however, that our intention is not to propose a model for teaching or assessing such skills. Rather, the effort should be understood as a contribution to the ongoing discussion regarding the best possible methods for building an education environment that enhances the development of these skills.

Factors related to teachers, such as gender, academic degree, years of experience, major and active learning training, might well help in interpreting results. Proposing solutions for each variable would, thus, be more productive. If there is, for example, a gender difference, then it would be sensibly tenable to suggest further explorations of the impact of other exogenous or endogenous variables that might have a bearing on the results, which is of course beyond the scope of this study.

\section{Methodology}

To reach its objectives, the study used a questionnaire that was given to a sample of 560 science teachers across the West Bank elementary schools (3-9 grades). A scale developed by Ravitz et al (2012) was used to test 48 practices across 8 major categories: Critical Thinking Skill, Collaboration Skills, Communication Skills, Innovation Skills, Self Direction Skills, Global Connections, Local Connections and Using Technology as a Tool for Learning. In addition to the data consistency achieved by the Ravitz scale (with internal consistency of $0.90-0.95$ ), the author carried out a pilot survey of 30 science teachers to achieve efficiency in testing and verify the survey questionnaire before executing the large-scale survey. The consistency coefficient was calculated using a Cronbach's alpha with a value of 0.81-0.85, which is indicative for the purposes of the study.

Prior to conducting our analysis, we examined all variables by means of SPSS for accuracy purposes. For better selection of the most appropriate testing model, we examined the normality/non-normality of data. We particularly used Kurtosis and Skewness test- which rejects the hypothesis of normality when the p-value is less than -1.96 or more than 1.96. Results of the test showed normality of data. An independent $t$ test was then used to determine whether the sample has been generated by a process with a specific mean. Because there are more than one layer within each variable, the study used a one-way analysis of variance (ANOVA) to calculate the differences. To compare the means for different items within the same variable, the author used Fisher's Least Significant Difference (LSD) test.

\section{Results and Discussion}

Table 1 below shows the distribution of respondents by teacher-related variables. Much literature has discussed the 21st century skills. However, many studies appear to talk less about the teachers themselves. Questions about teachers being life- long learners, innovative and creative should always be considered if a reliable account is to be given regarding the integration of such skills in the teaching/learning process. Teacher productivity are linked to a host of factors such as sex, academic degree, years of experience, teacher major and active learning training. 
Table 1. Distribution of respondents by variable

\begin{tabular}{llll}
\hline Variables & & Number (560) & Percentage \\
\hline Sex & Male & 176 & $31.4 \%$ \\
Academic degree & Female & 384 & $68.6 \%$ \\
& Diploma & 40 & $7.1 \%$ \\
& Bachelor & 376 & $67.1 \%$ \\
& Master & 128 & $22.9 \%$ \\
Years of experience & PhD & 16 & $2.9 \%$ \\
& $1-5$ & 56 & $10 \%$ \\
& $6-10$ & 112 & $20 \%$ \\
Major & $>10$ & 392 & $70 \%$ \\
& Biology & 136 & $24.3 \%$ \\
& Physics & 56 & $10 \%$ \\
& Chemistry & 88 & $15.8 \%$ \\
& General Science & 80 & $14.3 \%$ \\
Active Learning & Methods & 136 & $24.2 \%$ \\
& Others & 64 & $11.4 \%$ \\
Total & Yes & 416 & $74.3 \%$ \\
& No & 144 & $25.7 \%$ \\
& & 560 & $100 \%$ \\
\hline
\end{tabular}

$3.1 \mathrm{Sex}$

Table 2. A t test for sex

\begin{tabular}{llllll}
\hline Skill category & Sex & Mean & Std. Deviation & t-value & Sig. (2-tailed) \\
\hline Collaboration skills & Male & 3.1439 & .79958 & -5.773 & .000 \\
& Female & 3.6493 & .61798 & -5.253 & .000 \\
Communication skills & Male & 3.1636 & .84611 & -4.379 & .000 \\
& Female & 3.5833 & .69322 & -4.069 & .000 \\
Creativity and innovation skills & Male & 3.2818 & .90497 & -2.820 & .005 \\
& Female & 3.5542 & .66787 & -2.525 & .013 \\
Self-direction skills & Male & 3.0649 & .99233 & -.661 & .509 \\
& Female & 3.1369 & .77019 & -.602 & .548 \\
Global connections & Male & 2.4924 & .96619 & .841 & .401 \\
& Female & 2.3958 & .85589 & .804 & .423 \\
Local connections & Male & 2.8818 & .94084 & -.131 & .896 \\
& Female & 2.8958 & .77876 & -.122 & .903 \\
Using technology as & Male & 3.2784 & .84667 & -.049 & .961 \\
a tool for learning & Female & 3.2839 & .86781 & -.050 & .961 \\
Critical thinking skills & Male & 3.3864 & .78522 & -1.506 & .133 \\
& Female & 3.5278 & .70264 & -1.445 & .151 \\
$21^{\text {st }}$ Century Skills & Male & 3.0867 & .78377 & -2.015 & .045 \\
& Female & 3.2534 & .56684 & & \\
\hline
\end{tabular}

Obviously, female teachers are superior to their male counterparts across the board. However, the figures do not qualify to a statistically significant level. Our findings suggest that fewer males than females have the gut to cultivate the dispositions and competences of the 21 st century. If anything, female teachers are more flexible and they tend to excel in teaching sciences. The question of teacher sex differences should mean questions about how pupil achievements are measured and in what context. Plus, being able to teach science requires the ability to communicate effectively and comprehend abstract ideas; thus the female advantage in creative teaching and innovation should be helpful in explaining the differences.

However, there is little evidence to show that females are superior to males in terms of cognitive abilities. And research to date has shown that males and females are born with equivalent creative potential. If this is true, then sex differences might be interpreted in terms of the environment influence. Palestinian female teachers find a teaching job rewarding both socially and financially. On the one hand, working women are socially respected as 
they are believed to be major contributors to development. On the other, because females are not the main income producers for Palestinian households, they are well satisfied with a job teaching salary, and they are always afraid of losing it; hence their dedication for the profession. By contrast, men- the main income producers for households- do not find a teaching job satisfactory and it can hardly provide for the basic needs of their families, and thus they are somehow reluctant to give their job more time and effort.

\subsection{Academic Degree}

Table 3. One Way ANOVA test for Academic Degree

\begin{tabular}{lll}
\hline Skill Category & F value & Sig. \\
\hline Collaboration skills & 3.775 & .011 \\
Communication skills & .530 & .662 \\
Creativity and innovation skills & 1.037 & .377 \\
Self-direction skills & 2.386 & .069 \\
Global connections & 4.927 & .002 \\
Local connections & 3.328 & .020 \\
Using technology as a tool for learning & 9.541 & .000 \\
Critical thinking skills & 5.617 & .001 \\
21st Century Skills & 2.949 & .033 \\
\hline
\end{tabular}

In general, the aggregate values derived from the academic degree variable are significant. In five (out of eight) skill categories, the $\mathrm{F}$ values (or ratios of variances) are particularly remarkable, with values well higher than the critical point. The figure for using technology as a tool for learning is especially interesting. This comes as no surprise in a context where almost all houses in the West Bank are connected to the internet. Today, almost all schools in the West Bank have computers and internet access points. Labs at most schools are built to accommodate modern technological systems that create a semi-augmented reality. However, whether students are benefitting from this environment to develop their life skills or not remains debatable. Developing critical thinking skills, fostering collaboration, helping students building global connection competences, and local connections abilities are other areas where teachers seem to have done a good job, with F values of 5.617, 4.927, 3.775 and 3.328, respectively. There is no obvious reason why teachers were successful in these constructs, but it could be safe to conclude that three of these five categories are classified under participatory competencies (which also include local connections skills and communication practice), and they are based on technology.

Table 4. The Results of LSD test for Academic Degree

\begin{tabular}{lllll}
\hline Academic Degree & & Mean Difference (I-J) & Std. Error & Sig. \\
\hline Two-year College Diploma & Bachelor & -.28486 & .15041 & .059 \\
& Master & $-.45520^{*}$ & .16382 & .006 \\
Bachelor & PhD & -.47884 & .26752 & .075 \\
& Master & -.17034 & .09255 & .067 \\
Master & PhD & -.19398 & .23086 & .401 \\
& PhD & -.02364 & .23981 & .922 \\
\hline
\end{tabular}

*. The mean difference is significant at the 0.05 level.

The only significant difference, as the Table shows, is that between a Two-year College Diploma Degree and a Master's Degree (0.45520). This is natural because those with a Two-year College Diploma Degree usually teach lower grades (3-5) - where training for kids tends to be less extensive, while those with a Master's degree usually teach higher grades (6-9), where students in this age group are grown enough to receive training and build their competences. The differences between other academic degrees (Masters, $\mathrm{PhD}$ and Bachelor) are not statistically significant. This is a common sense because the education system in West Bank does not differentiate between teachers based on their degree. Whether they hold a bachelor, a Masters or a $\mathrm{PhD}$, teachers take the same teaching roles and loads. 


\subsection{Years of Experience}

Table 5. One Way ANOVA test for Years of Experience

\begin{tabular}{lll}
\hline Skill Category & F value & Sig. \\
\hline Collaboration skills & 1.404 & .247 \\
Communication skills & 9.067 & .000 \\
Creativity and innovation skills & 2.080 & .127 \\
Self-direction skills & 2.129 & .121 \\
Global connections & 13.871 & .000 \\
Local connections & 18.583 & .000 \\
Using technology as a tool for learning & .846 & .430 \\
Critical thinking skills & 1.458 & .234 \\
21st Century Skills & 6.497 & .002 \\
\hline
\end{tabular}

The variable "years of experience" seems to be one of the most important factors (only second to "active learning', as we will see later) in determining the level of skill-building at elementary schools, with an overall significant value of 6.497 (or sig. value of .002). Interestingly, though, the values are extreme, with local connections and global connections cultivation as high as 18.583 and 13.871, respectively, and using technology as a tool for learning as low as .846. Now this is a big difference that needs to be interpreted. Below, we present the results of an LSD test which can shed light on the correlation between different items (1-5 year experience, 6-10 year experience and more than 10 years of experience) and variations in values.

Table 6. The Results of LSD test for Years of Experience

\begin{tabular}{lllll}
\hline (I) Experience & Mean Difference (I-J) & Std. Error & Sig. \\
\hline $1-5$ & $6-10$ & -.19708 & .14669 & .180 \\
& $>10$ & .14510 & .12805 & .258 \\
$6-10 \quad>10$ & $.34218^{*}$ & .09603 & .000 \\
\hline
\end{tabular}

*. The mean difference is significant at the 0.05 level.

Teachers with 6-10 years of experience in teaching reported noteworthy efforts to foster the 21st century skills, with 0.34218 difference in their mean of skill development compared to other experience groups. Teachers within this group are still young enough to acquire dynamic competences and deliver them efficaciously to their pupils. However, it is not only about being young or old. Teachers within the 1-5 years group are younger, yet the figures related to them are not significant. At the same time, if it is about long years of experience, then one would expect the $>10$ years group to show better results. Teachers within the 6-10 group must have received effective training. Undoubtedly, teacher development is a professional growth that comes as a result of gaining increased experience, constant training and exploring teaching approaches in a systematic manner.

\subsection{Teacher's Major}

Table 7. One Way ANOVA test for teacher's major

\begin{tabular}{lll}
\hline Skill Category & F value & Sig. \\
\hline Collaboration skills & 3.969 & .002 \\
Communication skills & 4.866 & .000 \\
Creativity and innovation skills & 6.094 & .000 \\
Self-direction skills & 5.574 & .000 \\
Global connections & 7.809 & .000 \\
Local connections & 8.078 & .000 \\
Using technology as a tool for learning & 10.307 & .000 \\
Critical thinking skills & 2.630 & .024 \\
21st Century Skills & 6.946 & .000 \\
\hline
\end{tabular}

All categories showed positive correlation between teacher's major and the ability to develop the 21st century skills. The science subject at Palestine's elementary schools is taught by teachers who obtained degrees in physics, biology, chemistry, methods of teaching science, general science education, and other specializations. Any of these can be a candidate for teaching the science subject. In Table 8 below, we present an LSD test to 
compare the results of these five groups and find out the most determining factors within this variable.

Table 8. The Results of LSD test for teacher's major

\begin{tabular}{lllll}
\hline Teacher's major & & Mean Difference (I-J) & Std. Error & Sig. \\
\hline Biology & Physics & $-.51565^{*}$ & .13793 & .000 \\
& Chemistry & $-.49694^{*}$ & .11884 & .000 \\
& General Science & .06296 & .12240 & .607 \\
& Methods & -.04702 & .10534 & .656 \\
Physics & Others & -.14740 & .13168 & .264 \\
& Chemistry & .01871 & .14850 & .900 \\
& General Science & $.57862^{*}$ & .15136 & .000 \\
& Methods & $.46864^{*}$ & .13793 & .001 \\
Chemistry & Others & $.36825^{*}$ & .15895 & .021 \\
& General Science & $.55991^{*}$ & .13419 & .000 \\
General Science & Methods & $.44993^{*}$ & .11884 & .000 \\
& Others & $.34954^{*}$ & .14271 & .015 \\
Methods & Methods & -.10998 & .12240 & .370 \\
& Others & -.21037 & .14568 & .150 \\
& Others & -.10039 & .13168 & .447 \\
\hline
\end{tabular}

*. The mean difference is significant at the 0.05 level.

Apparently, teachers who obtained a degree in physics and chemistry appear to be doing a good job in nurturing innovative dispositions, with a mean difference of .51565 for the former and .49694 for the latter. This might be attributed to the fact that students majoring in physics and chemistry at higher education institutions do a lot of training, without which a student cannot pass many of the courses offered. Part of each teaching module within physics and chemistry majors at universities is how to train students on the best ways to tackle a problem and apply logical reasoning to arrive at a solution. Not only this, these students are expected to use technological tools to perform tests and analyze data. Therefore, they acquire effective competences long before they become teachers. Once, they teach science at elementary schools, they transfer the competencies they have acquired to their young learners.

\subsection{Active Learning Training}

Active learning is a method of teaching which has as its main goal engaging learners and encouraging them to learn through in-class discussions, case studies, problem solving and role play, among other things. All of these must be directed toward engaging learners in higher-order thinking tasks such as analysis, synthesis, and evaluation (Renkl et al, 2002). For the purpose of this study, the figures given below are for teachers who received training on different domains within active learning. 
Table 9. A t test for Active Learning Training

\begin{tabular}{|c|c|c|}
\hline \multirow{2}{*}{$\frac{\text { Active Learning }}{\text { Collaboration }}$} & \multicolumn{2}{|c|}{ Mean Std. Deviationt-valueSig. (2-tailed) } \\
\hline & YES3.5769.75035 & 3.490 .001 \\
\hline & NO 3.2407.54879 & 4.050 .000 \\
\hline \multirow[t]{2}{*}{ Communication } & YES3.5115.77787 & 2.241 .026 \\
\hline & NO 3.2778.71724 & 2.331 .021 \\
\hline \multirow[t]{2}{*}{ Critical thinking } & YES3.5192.79832 & 1.906 .058 \\
\hline & NO 3.3222 .61581 & 2.158 .032 \\
\hline \multirow[t]{2}{*}{ Self-direction } & YES3.2170.83002 & 3.528 .000 \\
\hline & NO 2.8175 .82335 & 3.542 .001 \\
\hline \multirow[t]{2}{*}{ Global connections } & YES2.4712.91784 & 1.437 .152 \\
\hline & NO 2.2963 .80210 & 1.534 .127 \\
\hline \multirow[t]{2}{*}{ Local connections } & YES2.9769.82816 & 2.965 .003 \\
\hline & NO 2.6444 .79592 & 3.023 .003 \\
\hline \multirow[t]{2}{*}{ Innovation } & YES3.3606.88658 & 2.622 .009 \\
\hline & NO 3.0556.73664 & 2.867 .005 \\
\hline \multirow[t]{2}{*}{ Technology utilizatio } & nYES3.5641.74222 & 3.193 .002 \\
\hline & NO 3.2500 .64822 & 3.410 .001 \\
\hline \multirow{2}{*}{ All } & YES3.2747.66322 & 3.301 .001 \\
\hline & NO 2.9881 .54442 & 3.631 .000 \\
\hline
\end{tabular}

All surveyed teachers reported that they received active learning training through development programs, supervision, in-service training, capacity building, seminars, workshops and conferences. They also reported that they have transferred the competences they gained to their students. It, however, remains crucial to consider not only whether they really delivered such training, but also the way they did this. In its 2017-2022 Strategy, the Ministry of Education found that only 30 percent of the activities done in elementary schools can be said to be directed to skill-building, while 64 percent of activities are based on memorizing and abstract knowledge feed, which brings into the question the efficiency of the methods the teachers currently use to deliver education (MOE, 2017).

\section{Conclusion}

Our findings suggest that in West Bank's elementary schools, advancing toward the 21st century is being recognized. Back in the years leading to the second decade of the 21 st century, our formal education allowed for limited, often traditional, methods of teaching. The education trends then focused on technology as an end rather than a tool that can facilitate learning. The curriculum relied on memorizing and indoctrination rather than on productive comprehension and reasoning. Schools behavior rarely worked to encourage students, and the main focus was on competition not cooperation, and on grades not real performance.

In the few past years, however, education practice has seen remarkable developments. The landscape is still promising, and there is progress, but the pace of transformation is not very fast to usher a breakthrough in the short term. The role of teachers in fostering young learners' competencies is still below the expectations. The financial and human resources mobilized for this purpose are huge, and they should have delivered much better results.

We have seen that science teachers at West Bank's elementary schools have indeed received training on active learning (as is evident in Table 9), but it seems that their performance with respect to training their pupils on these skills has not so far reached a level where we can conclude that our young generations are fully equipped with the competencies that allow them to contribute effectively to future development initiatives. This might be attributed to many factors, and to provide adequate answers, much research has to be done, and the initiatives at the local level are not exhaustive- further studies are still needed to provide accounts of the underlying reasons behind the existing gaps in developing those skills.

Education is a system of interdependent elements that work together to maintain that system and support its functioning. The point is that if we think of solutions to some existing gaps, we can't talk about one element as though it exists independently of others. We cannot, for example, blame the teacher and turn a blind eye to discrepancies within other constituents. By the same token, one might need to talk of the curriculum itself as a gap. In its current form, the curriculum does not take into account some important factors, such as students' interests, new global trends in teaching/learning, links between classroom activities and daily life and students' 
differences. However, literature suggests that the 21st century competences are not content knowledge-based (see, for example, Dede, C. (2009)). By extension, they are independent of the curriculum, which renders any effort to measure them through curriculum useless. We might also need to consider whether the system allows schools to incorporate extra-curricular activities that foster life skills, including the methods students should take to deal with the environment, such as skills acquired by scouts, DIY skills, as well as skills in dealing with large data and knowledge resources. If our education system changes to be more responsive to today's life needs, we will definitely have students who can adapt to changes, respond to problems, discover available resources, build local development models, and invest in technology.

\section{References}

AWRAD and CARE International. (2015). Skills Gaps and Development in the Occupied Palestinian Territory (Rep.). Retrieved from http://www.awrad.org/files/server/care\%20english\%20report\%20\%202015.pdf

Dede, C. (2009). Comparing Frameworks for "21st Century Skills". Retrieved from http://sttechnology.pbworks.com/f/Dede_(2010)_Comparing Frameworks for 21st Century Skills.pdf

Hunt, J. (1979). Pocket Dictionary of Quotations. UK: Hamlyn.

Kotrlik, J., \& Redmann, D. (2009). A trend Study: Technology Adoption in the Teaching-Learning Process by Secondary Agriscience Teachers-2002 and 2007. Journal of Agricultural Education, 50(2), 62-74. https://doi.org/10.5032/jae.2009.02062

Ministry of Education and Higher Education. (2013). Monitoring and Evaluating Report, Ramallah, Palestine.

MOE. (2017). EDUCATION SECTOR STRATEGIC PLAN 2017-2022 (Rep.). Palestine: MOHE. Retrieved from https://www.mohe.pna.ps/Portals/0/MOEHE_Resources/EDUCATION\%20SECTOR\%20STRATEGIC\%20 PLAN\%20\%20\%202017-2022.pdf?ver=2017-12-19-022932-367

Naqa, S. (2011). The level of creative thinking among students in high school in the scientific culture and the degree of encouraging science teachers to them from their point of view. IUG Journal of Humanities Research, 19(1), 167-207. Retrieved from http://www.iugaza.edu.ps/ar/periodical

Ramzi, Q. (2001). Science Teachers role in nurturing creative thinking for eighth graders. Retrieved from http://thesis.mandumah.com/Record/205644

Ravitz, J., Hixson, N., English, M., \& Megendoller, J. (2012). Using project-based learning to teach 21st century skills: Findings from a statewide initiative, presented at American Educational Research Association Conference, Vancouver. Retrieved from https://www.researchgate.net/publication/258188193_Using_project_based_learning_to_teach_21_st_centu ry_skills_Findings_from_a_statewide_initiative_Jason_Ravitz_Buck_Institute_for_Education

Renkl, A., Atkinson, R. K., Maier, U. H., \& Staley, R. (2002). From example study to problem solving: Smooth transitions help learning. Journal of Experimental Education, 70(4), 293-315. https://doi.org/10.1080/00220970209599510

UN. (2009). The Millennium Development Goals Report 2009 (Rep.). UN.

Zidan, A., \& Odeh, F. (2007). The Degree of Using Creative Thinking Style by the Lower Basic Teachers of Science in the District of Hebron. IUG Journal of Humanities Research, 16(2), 667-691. Retrieved from http://www.iugaza.edu.ps/ara/research

\section{Copyrights}

Copyright for this article is retained by the author(s), with first publication rights granted to the journal.

This is an open-access article distributed under the terms and conditions of the Creative Commons Attribution license (http://creativecommons.org/licenses/by/4.0/). 